\title{
Lessons on the political coordination of knowledge and innovation policies
}

\author{
Dietmar Braun
}

\begin{abstract}
The article takes up the main questions developed in the introduction and endeavours to give a synthetic account of the findings in the various country studies in this special issue of SPP. In a nutshell, one can see an impressive account of reform activities concerning the improvement of the political coordination of knowledge and innovation policies. It turns out that internal coordination by way of a superministry might not be the optimal solution for coordination problems. External coordination under the influence of 'moral contracts' at the top-level of decision-making on the ministerial level and newly designed and delegated coordinating bodies at the agency level might be better ways to proceed. Policy-makers have to pay attention though to keep the balance between the pressing need for better political coordination and the need for an autonomous development of basic research, higher education, professional education, and technological application.
\end{abstract}

$\mathrm{T}$ HE OBJECTIVE OF THIS SPECIAL ISSUE of Science and Public Policy is to identify on the base of four country studies - the political conditions for adapting the political governance structure to dynamics in the knowledge space. Adaptation was mainly seen as the capacity to organise the 'machinery of government' in such a way that encompassing and far-reaching coordination, i.e. 'policy coordination' (see the introduction to this special issue), of the different institutional actors would become possible. The introduction to this special issue of Science and Public Policy evoked a number of possible hurdles that could complicate the adaptation process, such as the institutional complexity - in some cases also caused by federal structures - that comes into the game of governing the knowledge space; lacking leadership and/or strategic intelligence; cultural segmentation of organisational units and standard interests of actors. In addition, it was asked if 'internal coordination' by means of a 'superministry' would be the most advantageous way of reaching policy coordination. After having presented the four countries and

Professor Dietmar Braun is Directeur at the Institut d'Etudes Politiques et Internationales, Université de Lausanne, Anthropole, CH-1015 Lausanne, Switzerland. their ways to deal with these issues, what are the general lessons that we can draw for inspiring future political practice?

\section{Activities to improve coordination capacities}

After studying the four cases, the obvious fact is that each of them - and this is also confirmed by the numerous country studies we find in the OECD study (OECD, 2005) and in the Technopolis report (Arnold and Boekholt, 2003) - have been active in ameliorating their coordination capacities in one way or another. There is clearly an increased awareness of the linkage between dynamics in the knowledge space and the political organisation of coordination in the governance of the knowledge space. What is interesting, though, is how this awareness has come about. It has not simply been a matter of linear, functional adaptation to already ongoing integrating trends in the knowledge space. The causal chain has been different: In all countries of our population there was first the insight that — and this concerned above all the link between basic and technological research/application but more recently also education and professional education - a stronger integration on the 'operational level' of the knowledge space was needed in order to be prepared for future developments. 
Dietmar Braun has been Professor of Political Science at the Institut d'Etudes Politiques et Internationales of the University of Lausanne since 1996 . He has also been research councillor at the Swiss National Science Foundation since 2004, and was editor of the Swiss Political Science Review between 2001 and 2004. He is an active member of the European Network of Excellence PRIME. He has worked on topics linked to science and technology issues since the beginning of the 1990s, especially on research funding policies and funding agencies. He was editor of a special issue of Science and Public Policy on principal-agent theory and research policy in 2003

A stronger integration meant most of the time bringing the various sectoral operational institutions in the knowledge space closer together and inducing more cooperation. It was this process that had a backlash on political governance institutions: As political responsibilities for the various operational institutions were most of the time divided among several actors both at the level of ministries and agencies, integration at the operational level forced political actors to think about a stronger integration of their relationships. Therefore change processes on the operational level, induced by political steering, as a consequence led to pressure on the machinery of government.

Dynamics in the knowledge space have certainly been one driver for reform attempts with regard to political coordination but they have not been the only one. Another important driver that emerged from the discussion is without any doubt the European Research Area (ERA). This has led all four countries - and Switzerland was no exception despite not being a member of the EU - to think about uniting forces within the country. This can be seen in Germany with its 'internationalisation initiative'; in Switzerland where the 'international environment' is a central argument in the discussion on the creation of a superministry; in Finland where the Ministry of Trade and Industry has been assigned the task of organising a stronger interministerial collaboration in order to organise the Finnish response to the ERA and where the creation of the recent superministry on trade, industry, labour and regional development can be understood in a similar way; and finally in Denmark where the establishment of the Globalisation Council in 2005 was at least partly a response to the ERA.

The activities of revising the machinery of government varies between countries and to judge whether these revisions have been successful is often difficult, among other things because many reforms have only been recently established, for example, the reorganisation of the 'superministry' in Denmark in 2006, the revised University Conference in Switzerland in 2005, the reorganisation of the Ministry of Trade and Industry into a 'superministry' in Finland in 2008 or the various 'soft coordination procedures' which have been launched in Germany in 20062008. But the important point is that reforms have taken place everywhere.
The creation of the Ministry for Science, Science Consultancy and Technological Change in Denmark - though its name implies an encompassing view on matters of the knowledge space - cannot in the first instance be seen as an example for a reform envisaging better coordination as it was completely inspired by the logic of political coalition-building and served to satisfy only the demands of a small coalition partner. It lacked political support and cohesion. Subsequent additions and subtraction of divisions to this ministry confirm that it was most of the time the political logic and not the functional logic of adapting governance structure to dynamics in the knowledge space which played a role in reforms. This changed somewhat in 2001 with the creation of the 'superministry' of Science, Technology and Innovation, which signalled a stronger awareness of the necessity to react to changing integration demands in the knowledge space. A more substantial will to reform coordination capacities can, however, only be seen with the establishment of the Globalisation Council in 2005 and its publication of the Strategy for Denmark in the Global Economy report. This has launched without a doubt a new élan with regard to the development of more cohesive strategies among ministries. Its success cannot yet be estimated.

While Denmark has opted mostly but not completely for internal coordination within one ministry, Germany is the example of a country where major institutional reforms of governance structures favouring better coordination are lacking. The reorganisations that have taken place are a product of the general federal reform and cannot be understood in the context of dynamics of the knowledge space. Activities that are linked to the knowledge space the excellence initiative, the high tech strategy or the internationalisation initiative - have not changed the machinery of government but seem at least to lead to 'soft coordination', i.e. to more communication among ministries, stronger vertical coordination, and also to a revision of internal coordination in ministries. Whether it will be successful remains to be seen.

Switzerland has reformed some of its institutions and is still in the middle of a discussion on the merits of creating a superministry on education, research, and innovation. Its main reform linked to matters of the knowledge space consists in the strengthening of the University Conference, which has become the main strategic political body of the federal government and member states responsible for the development of the higher education landscape. As higher education institutions are both the major higher education and research institutions in Switzerland, the function of this body has become central for the governance of the four policy fields of the knowledge space: higher education, professional education, research, and technological development. If Switzerland would in addition introduce a superministry on the federal level, one could speak of a 
strong institutionalisation of coordination capacities that would have taken place then.

Finland, finally, has, in contrast to the other three countries, reacted very early and in a comprehensive manner. The well-known Science and Technology Council, which is still at the heart of political coordination in Finland, was established in 1987. Its policies have led to a positive development in the relationships between ministries, which have made the step from pure negative coordination to the development of common policies. The creation of the new Ministry of Employment and Economy marks the effort to engage in a broader perspective of organising innovation policies as it is no longer only policy areas that are directly linked to the knowledge space but also other fields of relevance, such as regional development or the labour market, that are integrated into coordination efforts to organise innovation policies.

In sum, the overview confirms what has been said in the beginning, that all countries have been and are still active in reforming their coordination capacities but they do it in different ways and to different degrees in terms of institutionalisation. Denmark and Switzerland have opted for a stronger institutionalisation of coordination capacities while Germany remains reluctant to change its governance structures and prefers to introduce more temporary and less binding mechanisms. Finland has for a long time not institutionalised coordination on the ministerial or agency level but built its positive performance above all on the guiding capacities of the Science and Technology Council, which instructed political institutional actors about ways to coordinate.

\section{Dealing with institutional complexity}

The most challenging issue for successful coordination of governance of knowledge and innovation policies is certainly the institutional complexity that underlies any reform of coordination capacities. The existence of three vertical governance levels cabinet, ministries, agencies - and at least two (and often more) horizontal levels demonstrate that political coordination cannot be the outcome of an

\section{The most challenging issue for successful coordination of governance of knowledge and innovation policies is certainly the institutional complexity that underlies any reform of coordination capacities}

evolutionary process but must be designed and promoted. The main challenge is however not just institutional complexity but also the inherent tendencies of fragmentarisation and autonomisation, which must be overcome. The main question is how the countries have dealt with institutional complexity and inherent tendencies of fragmentation.

According to the introduction to this special issue of Science and Public Policy, governance modes leadership, strategic intelligence, and ministerial coordination (external and internal coordination) are the main mechanisms of dealing with institutional fragmentation. How have countries used these resources or means and what can we learn?

Before we raise each point separately we will briefly discuss federalism as one additional dimension in the institutional complexity of governing the knowledge space.

\section{Federal complexity}

The problem of institutional complexity has played a prominent role in federal countries, which had to deal with the 'federal divide' between the central level and member state level. The two federal countries in this special issue of Science and Public Policy have been deliberately chosen in order to understand how this dimension would affect coordination capacities in comparison to unitary states.

As expected, one can state on the base of our two federal cases that the federal dimension is an additional hurdle to overcome and that it increases transaction costs of coordination to a considerable extent. Federalism is not only important; it is omnipresent and, given the concurrency of competences, determines coordination discussions with regard to the knowledge space on almost every occasion.

In Switzerland the reorganisation of governance of higher education institutions, which at the same time concerns also the research and technology field, has been dominated by attempts to find a consensus between the cantons, which are responsible for universities, and the federal government, which not only has two technical universities of its own and co-finances cantonal universities but is also responsible for a substantial part for higher professional education institutions. In the end the institutionalisation of federal coordination has been achieved and now allows for a stronger integration of higher education institutions in the knowledge space as well as between governing institutions, including two federal ministries.

In Germany the federal government and member states have been endeavouring to coordinate their efforts for quite some time in the Science Council, the Conference of Education Ministers (KMK) and in the area of joint tasks (financing of extrauniversity institutions). On the other hand we do see almost no efforts to coordinate research and innovation policies between both territorial levels. The judgment on institutionalised federal coordination is 
negative with regard to the promotion of overall coordination capacities: The KMK has seldom been instrumental in developing common policies and was not set up to coordinate different policy areas; the financing of extra-university institutions was not inspired by attempts of developing joint policies. The only more positively regarded institution, the Science Council, in which scientists, federal and member state representatives participate, has been important in launching discussions and delivering useful analysis but is conceived neither as a policymaking body nor as a coordinating institution.

Recent developments have made cross-sectoral policy coordination in Germany even more difficult: Contrary to tendencies in Switzerland, Germany is now going in the direction of separating concurrent tasks, among them responsibilities for higher education policy which are now clearly in the hands of member states while the federal government has just some influence in the joint monitoring and evaluation of universities. This means that, except for monitoring, Germany, has no institutionalised means of coordinating federalism with regard to knowledge policy areas. Higher education policies are under the sole responsibility of the member states; research and technology policies are not coordinated; and professional education is organised along the lines of a division of labour between the federal government and member states. Given the importance of both levels for the governance of the knowledge space, this is no good omen for future coordination capacities in Germany.

Switzerland has gone in a completely different direction from Germany, not only with regard to the joint organisation of higher education policies, which implicitly also link research and technology policies to the University Conference. In addition, Switzerland has in its new constitutional articles on education, which were adopted in 2006, clearly given the federal government the lead in matters of the knowledge space: it has the leadership in harmonising professional education and it can force cantons to harmonise in matters of primary and secondary education if there is no self-organisation; research and innovation policies are under authority of the federal government even if it must be shared with cantons in the University Conference. With these reforms, Switzerland has developed a more suitable authority structure in federalism in order to organise cooperation in the governance of the knowledge space than Germany.

There is one additional aspect of federalism, which we will not find in unitary countries, and that is the discussion on the congruence of governance structures between the federal and memberstate levels. This discussion plays a role in both countries but again in completely reverse senses. In Switzerland the federal government is induced to create a superministry for education, research and innovation among other things because member states have most of the time already done so. In
Germany the introduction of a superministry seems impossible according to Edler and Kuhlmann (see this special issue of Science and Public Policy) because member states have no such organisation. So, in one case federalism acts as a catalyst for more coordination at the central level and in the other case it prevents a stronger institutionalisation of coordination capacities.

All this only demonstrates that federalism is a primary hurdle political actors have to deal with to develop coordination capacities in the knowledge space. Given the concurrent competencies or divided competencies in knowledge policy areas, there is no escape from finding ways and means to coordinate actions between the federal government and member states if they want to adapt to dynamics in the knowledge space. This takes time and energy, as Switzerland demonstrates, but it is feasible.

\section{Governance modes}

How authority is exercised and how actor relationships are organised can be an important means to overcome resistance of actors to participate in coordination. There are various governance modes that are at the disposition of political actors, i.e. hierarchy, delegation, bargaining, or moral obligation.

Hierarchy It seems that at least one expectation mentioned in the introduction to this special issue of Science and Public Policy has been confirmed in this sense: 'hierarchy' is not the governance mode that is preferred in the machinery of government or even in the relationship between the governance and the operational level. Of course, one finds hierarchy in the machinery of government but that is often not for the good of developing coordination. The frequent reorganisation of the composition of ministries in Denmark and Germany - and to a lesser extent in Finland and Switzerland - demonstrates the decisionmaking powers of the prime minister and of the cabinet. Bureaucratic organisation can be changed by a simple pen stroke of political leaders. But this only means that the composition of ministries is often not conceived according to a functional logic but to a logic respecting power distribution requirements. At the same time it demonstrates that ministries are often not more than ad hoc aggregations of governance fields that will have difficulties in developing internal cohesion, nor do they need to. The isolated role of IT and telecommunication in the Danish superministry is an example. Hierarchy as a governance mode is therefore omnipresent in the machinery of government. The question is whether it is also used in favour of developing coordination capacities. Let us have a brief look at the various vertical levels:

- Hierarchy seems not to govern relationships between the cabinet and ministries. In all four countries, ministries seem to have a relatively autonomous status, limiting direct powers of the 
prime minister or the cabinet. This is an effect of coalition governments that attribute posts of ministers to different parties that see ministries as their strongholds. The influence on ministries is only strong if all participants in the cabinet have decided on a joint strategy, but this is a different governance mode (see below).

- Hierarchy cannot be an option on the ministerial level because ministers are peers and not subject to authority relationships. The only hierarchical role can be attributed to the finance minister who can accept or refuse the financing of the ministerial budget. The finance minister has no coordinating role though.

- The working of hierarchy within ministries is difficult to assess. Several reasons were given in the introduction why it would not work, depending above all on the 'span of control'. Larger ministries with an accumulation of various policy areas make it difficult for the minister to use hierarchical authority because of lack of information and time restrictions. Divisions have in general a considerable autonomy. From the country studies presented we can at least deduce that the limitations of the use of hierarchy also hold for our examples: the introduction of new public management methods in Finland and Denmark within ministries is a sign that previous hierarchical relationships were suboptimal. Edler and Kuhlmann report the strong fragmentation within the Ministry of Education and Technology and the difficulty in developing coordination. Simple orders apparently do not work. One cannot create coordination on the base of order. It needs either voluntary agreements or incentive structures for actors to do so.

- Hierarchical relations between ministries and agencies are not excluded. This is confirmed by the status of project agencies in Germany and the Commission for Technology and Innovation in Switzerland. But as was already stipulated in the introduction to this special issue of Science and Public Policy, agencies have often a semi-public or private status and are therefore protected from direct orders. In this case ministries have increasingly used another governance mode to have a stronger influence on these agencies, i.e. new public management (see below). One resource that governmental actors often have though is the hierarchical power to dissolve agencies, create new ones and to reorganise them in a substantial way. This is not always possible but in many countries it is. We will come back to this point below.

In sum, hierarchy seems not to be the right option for improving coordination capacities in governing the knowledge space. Other governance modes are more prominent.

Delegation If one speaks of delegation one usually means today a governance mode that is based on

\section{Without any doubt, new public management and with it delegation have become omnipresent governance tools in countries not only to steer operational institutions or agencies but even divisions within ministries}

lessons from new public management, which is itself composed of different theoretical approaches; among them principal-agent theory, which attributes strategic powers to the higher level of the authority structure, and operational freedom to the lower 'agency' level.

Without any doubt, new public management and with it delegation have become omnipresent governance tools in countries not only to steer operational institutions or agencies but even divisions within ministries. Denmark and Finland are recent examples of this: Denmark decided in 2006 to reorganise the Ministry of Science, Technology, and Innovation by transferring personnel from the 'department' to the three 'agencies' within the ministry; and Finland united the divisions for university, science, and polytechnics in the Ministry of Education and introduced performance contracts to define their missions.

Advantages of new public management delegation that are often mentioned are the increased capacities of the 'principal' to steer or guide the activities of agencies as the separation between strategy development and operation allows for a concentration of activities and more time. The use of performance contracts helps to implement strategies and to control outcomes. The operational autonomy for agencies on the other hand gives them more room for manoeuvre and allows for more creativity. There is more flexibility in using resources.

New public management delegation is not conceived as a means for coordination but it can of course be used for this purpose. Denmark has done so with regard to operational institutions and Switzerland has tried to do the same with regard to its research funding agencies. It was, however, also observed in the country studies that new public management delegation can have opposing effects on coordination capacities, which is also recognised in general discussions on the utility of new public management in the public service: the operational autonomy of agencies leads to the creation of more self-determined actors who develop their own standard interests. As a consequence, even with performance contracts at hand, it becomes more difficult to bring these standard interests in line and impose coordination (Frissen, 1999). In this special issue of Science and Public Policy, Pelkonen et al 
consider new public management as a failure because of these tendencies. Koch confirms this observation for Denmark, and the attempt for imposed coordination between agencies in Switzerland simply failed as Griessen and Braun explain.

New public management delegation is obviously not built to develop networks and cooperation (Braun, 2006). It is developed to make vertical relationships more efficient but not horizontal ones. This is simply because it does not create incentive structures for coordination, even if one defines coordination as one of the objectives in the performance contract. It will usually be seen as a task that adds transaction costs without creating genuine benefits in the daily work of agencies. Only if cooperation would lead to real synergies, to a win-win game, would there be incentives for agencies to engage themselves in coordination. In this sense, it is doubtful whether new public management can really be a governance mode ameliorating the coordination between organisational units of the machinery of government, independent of the organisational level where it takes place.

Delegation can have its merits though if one creates institutions that have coordination as their raison d'être. In this case incentives to promote coordination exist. Special interministerial committees as they exist in Switzerland could in principle fulfil such a function but usually these committees are a place for exchanging information and at the best for bargaining about some common projects. These committees do not have an organisational identity of their own. The use of the new public management philosophy could reorganise such committees by using performance contracts and giving them a more permanent status with an organisational nucleus such as a secretariat, etc. This would be an incentive for these committees to be more inventive and determined in matters of coordination.

But overall new public management seems not to be the right governance mode to improve cooperation.

Bargaining and moral obligation What then is left as a suitable governance mode promoting political cooperation?

If hierarchy and delegation seem suboptimal, bargaining would be the next candidate in the list. The problem with bargaining is that it is, first, not applicable in vertical relationships but only in horizontal relationships and that, second, it means to find coordination agreements that entail 'Paretooptimal solutions' (see the introduction to this special issue of Science and Public Policy), i.e. agreements that promise more benefits than costs for all participants. Experience with bargaining situations as we find them, above all on the ministerial level, is not encouraging. Outcomes are usually negative coordination. Initiatives to promote better coordination usually fail. Bargaining does not seem to be promising for developing 'policy coordination'.
This statement must, however, be modified. Bargaining can be 'embedded'. The Finnish case, for example, mentions that bargaining may occur under the 'shadow of hierarchy': ministries can be obliged to bargain with each other. But even then solutions will be at the level of the lowest common denominator. Ministries may be obliged to develop some common policy programme but one will not find the development of common objectives and strategies on the basis of order, even if ministries can bargain about this. The 'shadow of hierarchy' does not seem to be the solution, then.

Another form of embeddedness is, however, more suitable for coordination as our empirical studies reveal and this is bargaining that is taking place under moral obligation. What does this mean?

Bargaining must take place after joint agreements on the main objectives and priorities in the governance of the knowledge space have been reached at the highest political level where ministers participate. The mode to reach such joint agreements should not itself be based on bargaining but be based on 'arguing' (Elster, 1986). The process is similar to constitution-making in general: The discussion must be about the development of long-term strategies and a long-term policy order. If this is the subject of the political discussion, general principles and longterm visions count and it becomes easier to abstract from selfish bargaining interests. The Finnish Science and Technology Policy Council and the Danish Globalisation Council, partly also the German Science Council, create such a forum for 'arguing'. The rationale of discussions here is not to develop concrete action plans on specific subjects but to develop an overall strategy for the country, based on problem recognition and problem-solving. If actors can be integrated in such a forum and an agreement can be reached, this will work as a moral obligation for actors and bind them to the agreement in the future. It does not preclude selfish interests that may reappear but one can use the resource of moral obligation to remind ministers to respect the objectives agreed upon and try to build on them.

This governance mode has successfully been used in Finland and Denmark, and has led to a much more positive attitude of ministries concerning cooperation and some obvious success in developing such cooperation in Finland. In Denmark it still remains to be seen whether the final outcome will be positive in a similar way. One important feature seems to be lacking for being successful in Denmark, though, i.e. the institutionalisation of 'moral obligation' by making the 'forum' a permanent one. The Globalisation Council was dissolved after having done its task. The Finnish Council has acted as permanent reminder for actors since 1987.

There are certainly also disadvantages to the use of moral obligation: Agreements are difficult to agree upon and hence it will be difficult to revise them so that they may become out of date and work as a conservative force as Pelkonen et al describe: 
As in the constitution, general principles and agreements cannot be easily be amended. This is the conservative aspect of such a governance mode. On the other hand it becomes possible during the reign of such an agreement to find the cooperation of all actors that have been involved. Moral obligation seems therefore to be a conditio sine qua non for achieving encompassing political coordination concerning the knowledge space.

While moral obligation may work on the ministerial level, it may be difficult to apply it to the agency level. As agencies are most of the time not part of such high-level political forums, they may not feel obliged by decisions taken there. The governance of the agency level remains therefore a problem in terms of improving coordination between agencies after hierarchy and delegation have proven to be suboptimal.

In this context one can come back, however, to one aspect of the hierarchy mode mentioned above and which might be helpful: Ministries often have the right to reorganise agencies, to dissolve and to create them. If this opportunity exists and ministries have found an agreement of cooperation between themselves, they might redefine the constitution of agencies or create new cross-sectoral institutions that have coordination between knowledge policy fields as a basic principle of action. As in the case of interministerial committees it would then be possible to use performance contracts to develop strategies and control success of coordination.

But such a decision should be seen as the final stage of a longer sequence of reforms in the machinery of government: first it would need the 'forum' on the highest level of politics and an agreement which defines the general policy in the governance of the knowledge space. This should induce ministries to develop more cooperative relationships and which then can decide by 'hierarchy' to redesign the set up of the agency level.

\section{Leadership}

Governance modes are an important resource to deal with institutional complexity. Political leadership was mentioned in the introduction to this special issue of Science and Public Policy as a second possibility. Leadership refers to the role of the prime minister or the cabinet to promote encompassing policy coordination.

The answer can be short: the autonomy of ministries is relatively strong in all four countries, which reduces the role of the prime minister or the cabinet in guiding policies in a unilateral way. Political leadership in the two federal states, Germany and Switzerland, has in general been weak. In Finland and recently in Denmark this has been somewhat different as prime ministers became involved in the 'forum', which was a very important symbolic step to give credibility to the forum and signal that the decisions of the forum will have the support of the

\section{Moral obligation seems therefore to \\ be a conditio sine qua non for achieving encompassing political coordination concerning the knowledge space}

government. And it is in this context that leadership seems to count: It can be important for the creation of a general and nation-wide consensus on knowledge and innovation policy.

Once such an agreement has been found, the political leader can exercise a role in the sense of 'moral obligation': he or she can personally remind the various institutional actors of their consent and put pressure on ministers to respect the agreement. In this sense leadership is important but it should not be confounded with hierarchical guidance.

\section{Strategic intelligence}

Strategic intelligence has been identified as a potential means to overcome selfish interests of political actors by the use of scientific knowledge that can 'rationalise' discussions. This may help to attenuate the institutional fragmentation of the machinery of government of course only if scientists opt for policy coordination or if they receive the official task of paying attention to the improvement of political coordination. In this respect one finds no case among our countries that has indeed used strategic intelligence for the development of coordination in an institutionalised way.

It is nevertheless illuminating whether and to what extent scientists and therefore strategic intelligence has access to political decision-making. This at least indicates the possibility of rationalising the discussions and introducing a problem-solving attitude in the discussions respectively.

Our four country studies demonstrate three things:

1. It is most likely that the scientific voice will be heard in 'forums' like the Finnish Council and the Danish Globalisation Council, where actors are obliged to 'argue' instead of bargaining. Though we do not have information to what extent the scientists that participated within the mentioned councils have indeed had an important influence on the decisions taken, there is no doubt that the forum prepares the ground for scientific arguments.

2. A 'corporatist' chamber such as the German Science Council, where scientists and politicians meet and in which all recommendations are first prepared by scientists before they are discussed by politicians, can be and has been a useful 
institution. Germany's problem has only been that the Science Council has no mandate to develop more encompassing policies or to take care of the political coordination between the different institutional actors. It would not be impossible, though, to introduce a further going mandate for the Science Council in this sense.

3. Scientific advisory bodies directly linked to the political leader have seldom had a major influence on strategy development or on political coordination. This is demonstrated by the various bodies that have existed until now in Germany and which were designed to advise the chancellor in developing above all a more future-oriented technology policy. And it is proven in the case of Switzerland where the Science Council has proven impotent to make itself heard by policy-makers despite its mandate to advise the cabinet directly in all matters concerning the strategy development in knowledge and innovation policy.

\section{External and internal ministerial coordination}

The final question we would like to address - and this also concerns dealing with institutional complexity - is the question of how to organise coordination at the level of ministries. The general option at the disposition of political actors is to organise policy fields of the knowledge space in two or more ministries (external coordination) or within one ministry (internal coordination).

In the introduction several expectations concerning both options were formulated:

- External coordination seems to cause a permanent struggle between standard interests of ministries and to favour negative coordination. Bargaining is generally the main governance mode, which means, as explained above, that only Paretooptimal outcomes are possible.

- Internal coordination has some advantages. A newly created 'superministry' can create a new élan in policies of the knowledge space; the development of inter-sectoral policies may be part of the constitution of the ministry; hierarchical powers within the ministry can be used to close ranks; and a superministry would lower transaction costs concerning the coordination of policy areas. Negative points mentioned were the possible exclusion of other relevant areas for knowledge and innovation policies; an increased competition with other ministries leading to a possible backlash in resources; a continuing internal fragmentation because of administrative cultural divisions and therefore still high transaction costs; the supposition that bargaining instead of hierarchy may prevail.

External coordination On the base of our empirical examples one can say that the expectations were justified: interministerial coordination remains in general at a low level. It is mostly negative coordination, which prevails if there are no joint agreements at the level of the cabinet. Spontaneous positive or policy coordination does not seem to evolve. And even if there are specialised interministerial institutions such as the 'steering committee' in Switzerland, this has not helped because these committees remain dependent on the initiatives and the good will of ministries. Of course we find other mechanisms - for example, the 'joint budget proposal' in Switzerland - that can at least force ministries to talk to each other and discuss the possibility of joint actions. But again this seems seldom to result in common action. If the knowledge area is divided up between two ministries - which is the case in Switzerland, Germany, and Finland, and even in Denmark there is still a Ministry of Education next to the superministry — one invariably finds different cultures and ways to see things between ministries, which makes cooperation difficult. Finland has nevertheless been able to overcome such retarding effects. Finland was able, without creating a superministry, to develop positive coordination, i.e. the formulation of certain common policies. And despite very different ministerial cultures, informal contacts are good.

Pelkonen et al are overtly positive about external coordination between ministries, which seems to be relatively well developed. This can only be explained, as already said, by the general consensus at the cabinet level, but also by the stability of the institutional setup and the development of trust relationships between ministries because of the long time that cooperative relationships had to develop. This does not mean that Finnish ministries would refuse competition or the strife for dominance, as the example of the leadership question in policies addressed to the European Union demonstrates. It certainly needs from time to time high-level initiatives to drive external coordination at the ministerial level further but in general this seems to be possible.

The message is therefore again that external coordination seems to be possible if a general consensus is found on policy priorities and strategies and coordination at the level of the cabinet that can trickle down to the ministerial level.

The examples in the other countries demonstrate the difficulties if such a general consensus has not been possible:

- One finds constant difficulties and unfriendly competition between the Ministry of Science, Technology, and Innovation and the Ministry of Education in Denmark.

- The relationships between the Ministry of Interior in Switzerland, responsible for education and science policy, and the Ministry of Economy, responsible for professional education, technology and innovation policy, are more in terms of mutual adjustment, negative coordination and occasional exchange of information than inspired by a sense of joint effort. 
- For Germany, Edler and Kuhlmann state that overall coordination is poor and that one does not see real efforts of coordination between the Ministry of Education and Technology, the Ministry of Economy and Industry and other sectoral ministries. Only - and this again confirms our expectations - because of the pressure of the EU and the internationalisation initiative which has been decided at the level of the cabinet do we see some efforts to ameliorate external coordination. The results are not yet clear.

This confirms the difficulties one could expect for external coordination of ministries. Spontaneous policy coordination is very unlikely and even mechanisms specifically designed to improve external coordination will fail as long as there is no general strategy that has been decided at the highest level of politics and that demands coordination efforts from ministries.

Internal coordination as an alternative seems not to be a solution. The Danish superministry, the Ministry for Science, Technology, and Innovation, is more an example confirming the arguments against the creation of a superministry. One notices according to Koch in this special issue a strong fragmentation between the divisions composing the ministry due to cultural splits. Such fragmentation even holds within the division for science, technology, and innovation. The mere implantation of different organisational and functional units within one ministry does not yet lead to a common vision and joint efforts. This needs time and an active strategy of building shared worldviews. Germany confirms this example within the context of the Ministry of Education and Technology: despite transverse divisions that are used to ameliorate internal coordination such cooperation has remained weak and fragmentation along the lines of funding programmes continues to exist (see Edler and Kuhlmann in this special issue).

Finnish policy-makers have discussed but refused to create a superministry for education, science, and technology. The reasons for that seem to be of general relevance: the fusion of previously separated organisational units belonging to different ministries might break down vertical ties (networks, and expertise) that are a very important asset for developing sectoral policies and also existing horizontal ties between divisions within ministries.

This is why - next to the other arguments against a superministry mentioned above - the creation of a superministry seems not to be the answer to coordination problems. The negative side effects seem very important and there is no guarantee that hierarchy works or that cultural segmentation can be overcome, at least not on the short or medium term. Transaction costs to create such a superministry are moreover very high given the breaking down of existing organisational arrangements.

\section{Searching for optimal solutions}

Is there then a recommendation that one can formulate on the base of these critical remarks? Is there an optimal solution for overcoming institutional fragmentation?

We think that, to give an answer to these questions, one should have a critical look at the functional need for political coordination itself. Political coordination cannot be an objective in itself, void of any content. It must be used to improve the interfaces between knowledge policy areas but one should be reminded that the development of higher education, professional education, technological application and basic research is not always dependent on interfaces. Each knowledge policy area continues to exist as an area of its own that needs special 'gardening'. This is why, for example, the creation of a superministry entailing all four fields may also be a danger as it may focus too much on coordination instead of also developing each area as such. It is for this reason that a political organisation that has latent coordination capacities that can be tapped but that also keeps strong capacities to develop each sectoral area independently would obviously be the ideal solution.

After having analysed the various options for organising political coordination, it seems to us that external coordination between ministries is still the best way to go, first of all because in this way vertical and horizontal ties of these ministries or their divisions can be maintained and therefore the sectoral development of policy areas be promoted. Moreover, because it avoids the problems that may appear with the creation of a superministry, such as rising transaction costs, rising competition and probably continuing cultural fragmentation problems. External coordination can, however, only work if - this is one of the central lessons of this special issue - an overall consensus on long-term policy goals and priorities can be reached that integrates the moral obligation to develop political coordination across knowledge policy areas. Such a consensus should be institutionalised within a high-level policy body that watches over the implementation of the consensus.

\section{External coordination can only work if an overall consensus on long-term policy goals and priorities can be reached that integrates the moral obligation to develop political coordination across knowledge policy areas}


If in addition one installs interministerial committees that have the sole task of developing interministerial cooperation, which obtain the status of organisation and which are bound by a performance contract, one would also have actors with a standard interest in the development of political coordination.

Such a view has of course repercussions for the organisation of the agency level. If external coordination prevails on the ministerial level it would be a mistake to strive for a fusion of agencies at the agency level. A more suitable way would be to introduce more 'redundancy' into the system, i.e. to create additional agencies that are specialised in preparing the coordination between policy fields. This of course will cause delimitation problems and competition with existing agencies but it has the advantage of freeing these agencies from engaging in an action that is overtly seen as an additional burden but not as a benefit.

The mentioned 'coordination group' in Denmark seems to be an example that goes in this direction though it is not conceived as an additional agency but as a truly overarching coordination body for the various research councils. It cannot yet be said whether this group can fulfil its function - similar experiences in the UK are not too favourable - but the idea seems to be right: an institutional actor is created that has a direct interest in coordination while the remaining actors in the system focus upon the development of their sector-specific tasks. In Denmark, everything will depend on the influence this coordination group has on the research councils and on the inherent interests of research councils to engage themselves in coordination activities. It is for this reason that we think that a body that has resources of its own to develop coordination activities in the field and which does not only act as a coordinating body of existing agencies might be the better and more promising idea.
In sum, political coordination of knowledge and innovation policy is not impossible and has been done quite successfully, for example in Finland, but it needs a number of conditions. The difficulties in developing such coordination in most countries point to the fact that these conditions are not easily achieved. Without the political will and skill nothing will be achieved and this political will can only be created within a forum-like structure at the cabinet level with a clear involvement of top policy-makers. The inclusion of strategic intelligence as a permanent rationalising resource seems also to be important. If the political will is clearly demonstrated at the cabinet level the creation of a superministry is superfluous and even unfavourable because it may endanger existing sectoral-specific activities. 'Enlightened' external coordination seems to be the better way. Political coordination should not substitute existing sectoral activities but be a latent means that can be called upon if necessary. The machinery of government should not be built on coordination structures. Sectoral and coordination structures should co-exist.

\section{References}

Arnold, Erik and Patries Boekholt 2003 Research and Innovation Governance in Eight Countries. A meta-analysis of work funded by EZ (Netherlands) and RCN (Norway).

Braun, Dietmar 2006 The mix of policy rationales in science and technology. Melbourne Journal of Politics, 31, 8-35.

Elster, Jon 1986 The market and the forum: three varieties of political theory. In Foundations of Social Choice Theory, ed. Jon Elster, pp. 103-132. Cambridge: Cambridge University Press.

Frissen, Paul 1999 Politics, Governance and Technology. a Postmodern Narrative on the Virtual State. Cheltenham: Edward Edgar.

OECD, Organisation for Economic Cooperation and Development 2005 Governance of Innovation Systems. Vol. 2: Case Studies in Innovation Policy. Paris: OECD. 